\title{
Erratum to: Measuring Spatio-temporal Trends in Residential Landscape Irrigation Extent and Rate in Los Angeles, California Using SPOT-5 Satellite Imagery
}

\author{
Ying-Jung Chen ${ }^{1}$ • Joseph P. McFadden ${ }^{1}$ • \\ Keith C. Clarke ${ }^{1}$ - Dar A. Roberts ${ }^{1}$
}

Published online: 14 October 2015

(C) Springer Science+Business Media Dordrecht 2015

\section{Erratum to: Water Resour Manage}

\section{DOI 10.1007/s11269-015-1144-2}

1. The running page title should be "residential landscape irrigation in Los Angeles".

2. The line (subheading) that says "2.5.1 Simple NDVI Threshold" should be deleted.

3. Section 3.1. The 3rd line says "WY2005-2007" but there should be a SPACE after "WY".

4. Section 3.4, the very first line of text that follows after Fig 4... The word "and" should be inserted right before "71.1 mm month-1".

5. The following is a higher resolution of Fig. 3.

The online version of the original article can be found at doi: http://dx.doi.org/10.1007/s11269-015-1144-2.

\section{Ying-Jung Chen}

hc10024@gmail.com

1 Department of Geography, University of California, Santa Barbara, 1832 Ellison Hall, Santa Barbara, CA 93106-4060, USA 
(a)
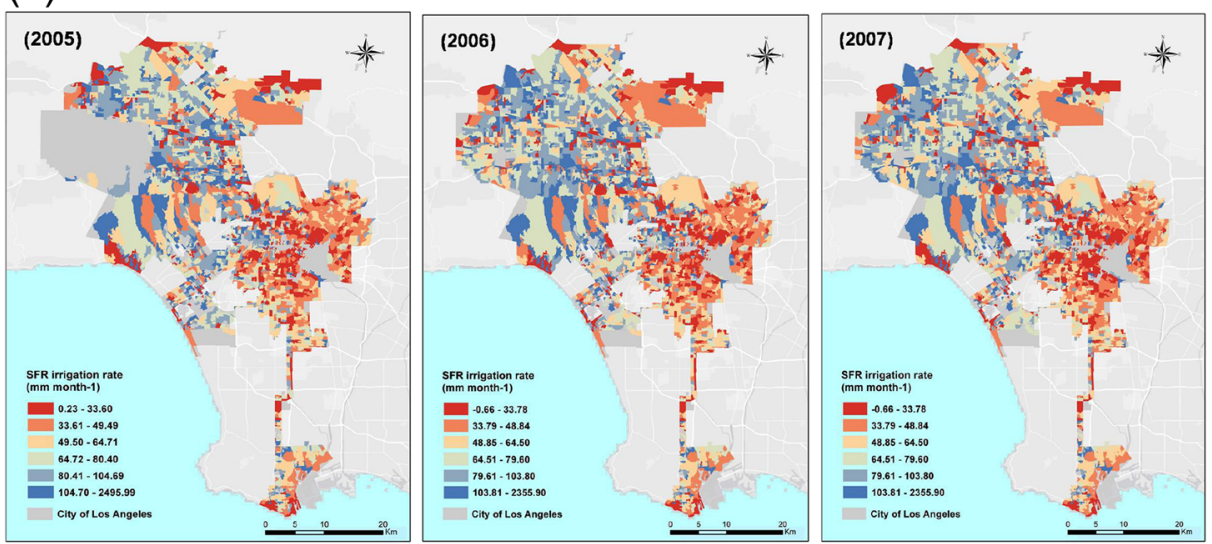

(b)
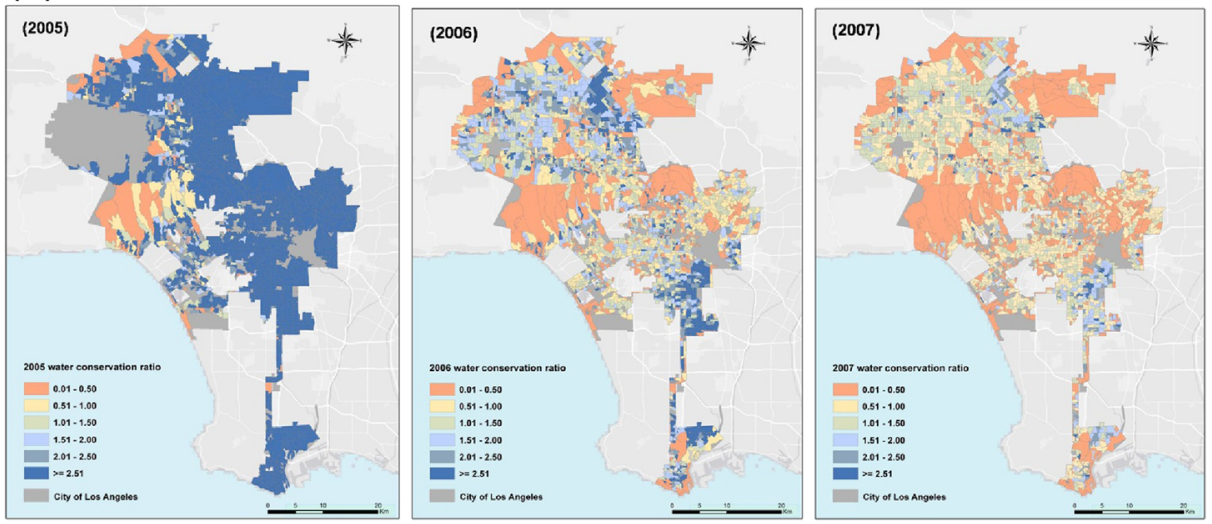

Fig. 3 a Irrigation rate of SFR parcels within each CR b water conservation ratio of estimated OWU to modeled vegetation water demand for all SFR parcels within each CR across the City of Los Angeles 